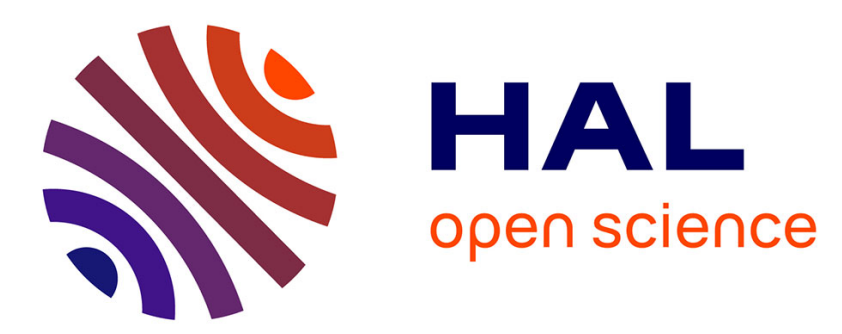

\title{
Characterisation of the transverse mechanical properties of carbon/carbon composites by spherical indentation
}

\author{
Marie Poitrimolt, Mohammed Cheikh, Gérard Bernhart, Vincent Velay
}

\section{To cite this version:}

Marie Poitrimolt, Mohammed Cheikh, Gérard Bernhart, Vincent Velay. Characterisation of the transverse mechanical properties of carbon/carbon composites by spherical indentation. Carbon, 2014, 66, p. 234-245. 10.1016/j.carbon.2013.08.063 . hal-01611612

\section{HAL Id: hal-01611612 \\ https://hal.science/hal-01611612}

Submitted on 4 Jul 2018

HAL is a multi-disciplinary open access archive for the deposit and dissemination of scientific research documents, whether they are published or not. The documents may come from teaching and research institutions in France or abroad, or from public or private research centers.
L'archive ouverte pluridisciplinaire HAL, est destinée au dépôt et à la diffusion de documents scientifiques de niveau recherche, publiés ou non, émanant des établissements d'enseignement et de recherche français ou étrangers, des laboratoires publics ou privés. 


\title{
Characterisation of the transverse mechanical properties of carbon/carbon composites by spherical indentation
}

\author{
Marie Poitrimolt ${ }^{a, b}$, Mohammed Cheikh ${ }^{a, b, *}$, Gérard Bernhart ${ }^{b}$, Vincent Velay ${ }^{b}$ \\ a Université de Toulouse, IUT de Figeac, ICA (Institut Clément Ader), EA814, avenue Nayrac, F 46100 Figeac, France \\ ${ }^{\mathrm{b}}$ Université de Toulouse, Mines Albi, ICA (Institut Clément Ader), EA814, Campus Jarlard, 81013 Albi cedex 09, France
}

The mechanical characterisation of the carbon/carbon composite in the transverse direc tion is essential for the design of braking discs. This paper presents a technique based on spherical indentation to identify the mechanical behaviour of such materials in the transverse direction.

After the presentation of the material properties as determined from static and fatigue compression tests, the indentation technique is described in detail. The characterisation technique used takes into consideration the transverse isotropy of these materials. The method used allows to identify the material behaviour in elastic and inelastic fields. Char acterisation of elastic parameters is carried out after identification of the Hertz law in the unloading indentation cycles. The hardening parameters and the elastic limit are identified by expressing the law of Hertz in strain/stress form.

The identified parameters are used in a simulation of an indentation test by finite element method. A good agreement is found between numerical and experimental results.

\section{Introduction}

Carbon/Carbon (C/C) composites have been under develop ment since the 1960s as thermo structural materials for high temperature applications such as in the case of aeronautical braking, motor sports, nozzles, etc. Their moderate density (less than 2), thermal properties such as a low coefficient of thermal expansion, and a large heat capacity at high temper ature (2.5 times higher than that of steel) as well as good mechanical properties up to $2000{ }^{\circ} \mathrm{C}$, make them indeed good materials for hot working structural elements.

This work is a part of a study on C/C composites for brake discs against steel discs in a lubricated environment for aerospace applications. Its aim is the characterisation of $\mathrm{C} / \mathrm{C}$ composites in the transverse direction to the plane of friction using the indentation technique. In a braking configuration, the brake discs are highly stressed in the transverse direction. With a very low coefficient of friction and particularly in a lubricated environment, the friction force is provided by increasing the load in the normal direction to the plane of friction. For sizing the C/C discs to support these load levels, accurate mechanical characterisation in the transverse direc tion is required.

In the literature, studies of $\mathrm{C} / \mathrm{C}$ composites for brake appli cations are typically oriented towards the study of the friction behaviour of these materials. Few studies have addressed the characterisation of these composites in transverse compres sion. For example, one can cite the works of Davies and Rawlings [1] and Douarche et al. [2] on the characterisation of these materials in compression. The behaviour of these materials in compression depends heavily on the specimen's geometry and particularly its thickness [1]. To remedy the

\footnotetext{
* Corresponding author: Fax: +33 565503061 .

E mail address: mcheikh@univ tlse2.fr (M. Cheikh).
} 
problems with respect to the influence of thickness in com pression tests, the specimen shall have a thickness equal to that of the disc. However, the brake discs are thin; typically $5 \mathrm{~mm}$ as thickness in our study. Realisation of the compres sion test on thin specimens with a local measurement of strain is more complicated.

To characterise these materials in the transverse direction, many authors have used nanoindentation techniques [3 8 ]. However, this technique only allows the material behaviour of components to be characterised, and not the composite it self. For the indentation technique used in this study, the dimensions of the indenters and the load levels allow a wider contact area to be tested. Subsequently this study estimates the mechanical characteristics of the composite and not the components of the composite. In contrast to a standard com pression tests, the experimental method developed here can be utilised to perform non destructive compression tests which allow the discs to be tested before their use.

\section{Material and experimental tests}

\subsection{Material structure}

The material used consists of a stack frame of fibres oriented in three directions: $0^{\circ}, 60^{\circ}$ and $60^{\circ}$, as shown schematically in Fig. 1. The fibres used are of the PAN (polyacrylonitrile) kind. To increase the delamination resistance of the frames, trans verse fibres are needled to form a $2.5 \mathrm{D}$ structure. The density, the length and the frequency of needling are part of the man ufacturing process and are not revealed by the manufacturer.

Pyrolytic carbon matrix is formed by Chemical Vapour Infiltration (CVI). The matrix grows concentrically with respect to the fibres and seems to form a sheath around the fibres. Its radial growth is steady around the fibres, or rather the fibre's bundles, that form the frames.

Fig. 2 shows an image of the disc surface observed by an optical microscope. The fibres thus appear as cylinders with a constant diameter, very smooth, mostly grouped in braids, and waving macroscopically. A comparison with a cable can be used to describe the structure of the fibre bundles as shown in Fig. 3(b) and (c). The mean diameter of the fibres is $9 \mu \mathrm{m}$ and the bundle thickness is between 150 and $250 \mu \mathrm{m}$. The $\mathrm{C} / \mathrm{C}$ composites are characterised by their poros ity induced by the forming process of the matrix. A porosity of an order of $8 \%$ is observed on the samples used. Cracks are also observed on these materials as shown in Fig. 3(a) This

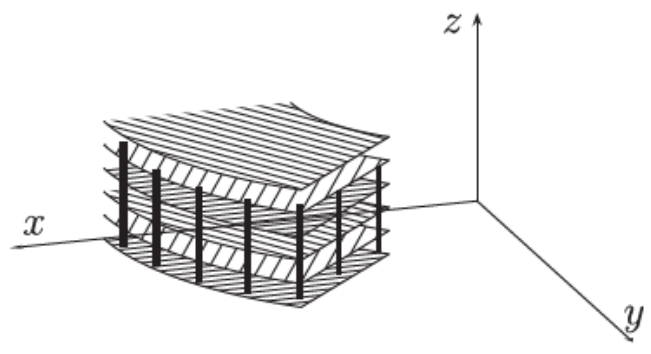

Fig. 1 - Representative diagram of the stack frames, the fibres direction and the needling.

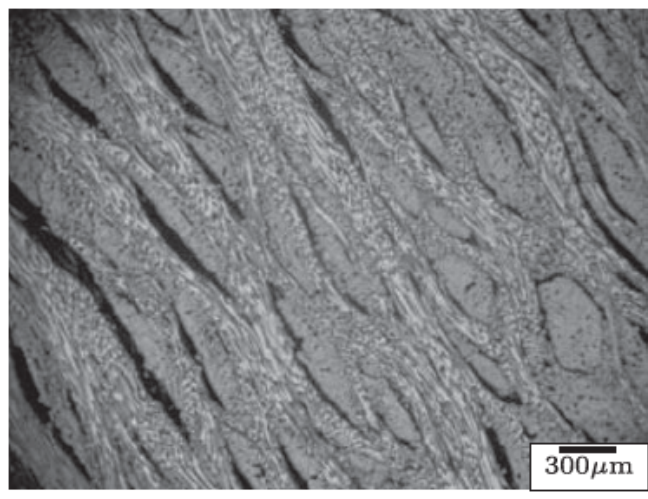

Fig. 2 - Optical microscope image of the transverse surface showing the architecture of the material.

cracking is attributed to the internal stresses induced by the cooling after the heat treatment is applied to the materials.

\subsection{Mechanical behaviour of the material}

To determine the overall behaviour of the material, a series of compression tests were performed. This series of tests in cludes seven compression tests on prismatic specimens of dimensions with the following mean values: $14.93 \times 15.1 \times$ $24.29\left(\mathrm{~mm}^{3}\right)$. The first five tests were aimed at identifying the mechanical characteristics of the $\mathrm{C} / \mathrm{C}$ in a compression test. The characteristic values obtained in this test will serve as a reference for the indentation test results.

The last two specimens were used to carry out fatigue tests in compression with imposed stresses. For both fatigue tests, asymmetric loading was imposed between 0 and $120 \mathrm{MPa}$. Two other compression tests with loading and unloading up to failure on two prismatic specimens of dimensions $22.31 \times 22.31 \times 22.0 \mathrm{~mm}^{3}$ were also achieved. Each loading cycle was incremented by a loading of $20 \mathrm{MPa}$ relative to the previous cycle. All tests were conducted on an MTS 810 fatigue machine with a capacity of $100 \mathrm{kN}$. The compression test was done in the direction perpendicular to the plies ( $z$ direction in Fig. 1). The supplier has not pro vided the dimensions of the plies. With an optical micro scope one can deduce an average of 48 plies through the thickness of specimens. The strain of the specimens in static and fatigue compression tests was measured by an exten someter (MTS 634.31F 24) with an elongation of $10 \mathrm{~mm}$ and an accuracy class of 0.5 .

The objective of the compression test with loading and unloading as well as the fatigue test is to bring out the nonlin ear behaviour of the material of interest. Indeed, all studies of the mechanical behaviour of $\mathrm{C} / \mathrm{C}$ composites show that these materials have nonlinear behaviour, either in the elastic or inelastic fields [9 11].

Fig. 4 shows the representative curve of the first series of tests of simple compression up to the failure of the specimen. The material behaviour can be considered as elastic up to a stress of $110 \mathrm{MPa}$. From this value to the failure of the mate rial at a stress of $220 \mathrm{MPa}$, the material is inelastic. In a first approximation, the material behaviour can be considered lin ear for both elastic and inelastic fields. An elasticity modulus 


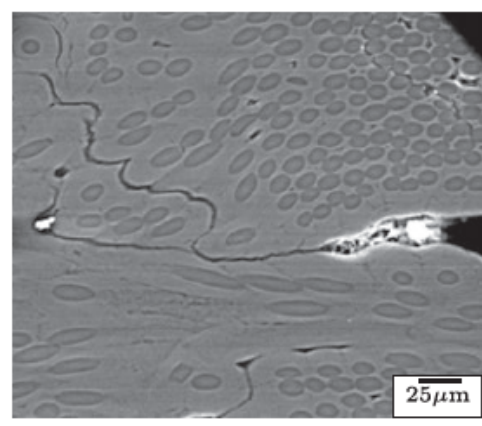

(a)

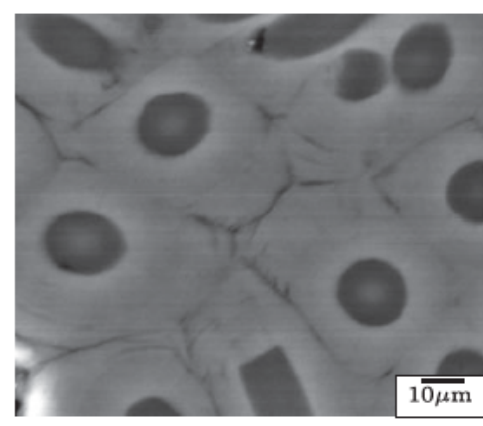

(b)

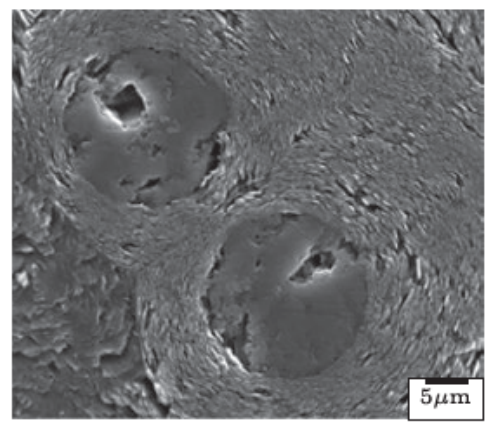

(c)

Fig. 3 - Image architecture obtained by SEM: (a) Matrix cracking, (b) Sheath shape of the matrix around fibres, c) Each sheath is composed by a layers arrounding the fibre.

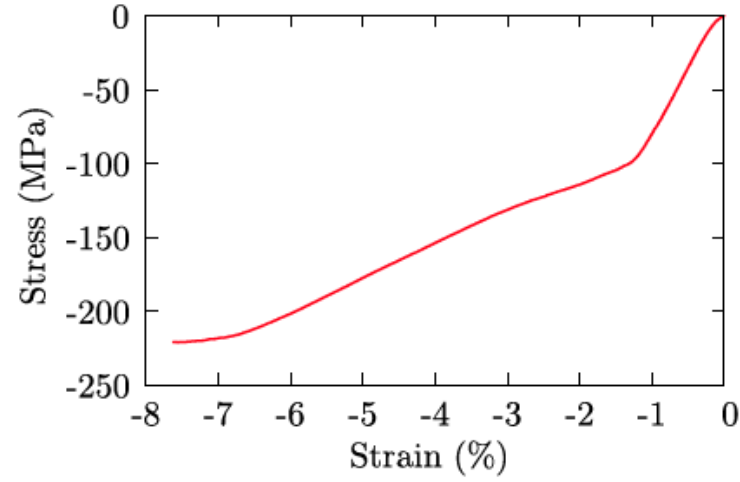

Fig. 4 - Characteristic curve obtained in compression test. (A colour version of this figure can be viewed online.)

of $E_{z} \quad 11.7 \mathrm{GPa}$ and a hardening modulus $\mathrm{H}_{\mathrm{zz}} \quad 2.22 \mathrm{GPa}$ can be deduced from these tests as shown in Fig. 5.

Fig. 6(a) shows the trend of fatigue cycles between the 50th and the 10,000 th cycles with increments of 100 cycles. The $110 \mathrm{MPa}$ initial elastic limit observed on the compression test is exceeded from the very first cycle. All fatigue cycles are in the elastic range after the hardening of the initial elas tic limit. Each cycle exhibits a non linear hysteresis loop with different loading and unloading phases. This hysteresis of loops is attributed to the friction that accompanies sliding at different scales of the material [12]. At the nanoscale, the sliding corresponds to the slip of the graphitic layer planes at crystal scale $[4,7]$ for either the fibres or the matrix.

Sliding at the mesoscopic scale [13] is attributed to the slip between the pyrocarbone concentric layers around fibres (Fig. 3(c)). At a higher scale, which could be considered as micro macroscopic, slips are attributed to sliding between the fibre and the matrix and the sliding at the crack level ob served in the material in a virgin state (Fig. 3(a)) or induced by the fatigue loading. With the development of fatigue cycles, the cracks at the microscopic scale become saturated, which corresponds to the shakedown of fatigue cycles and the satu ration of total strain observed in Fig. 6(a) and (b).

Fig. 7(a) shows the results of the compression test with loading and unloading. This curve confirms the nonlinearity of the elasticity observed in the fatigue tests. The hardening zone of the curve corresponds broadly to the shape of the lin ear hardening in the compression test shown in Fig. 4. A var iation in the slope of loading in the elastic range is observed among the different cycles. This variation is due to the dam age induced by the cracking of the matrix and the debonding between fibres and matrix. The material damage is also ob served on the fatigue cycles. Fig. 7(b) shows the 50th and

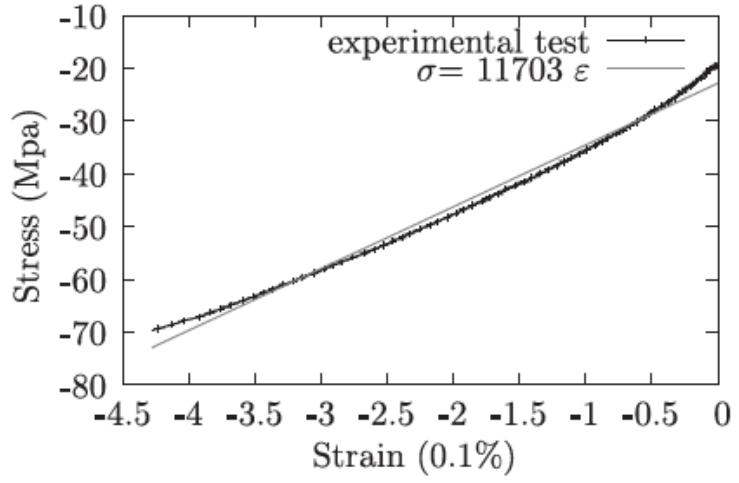

(a)

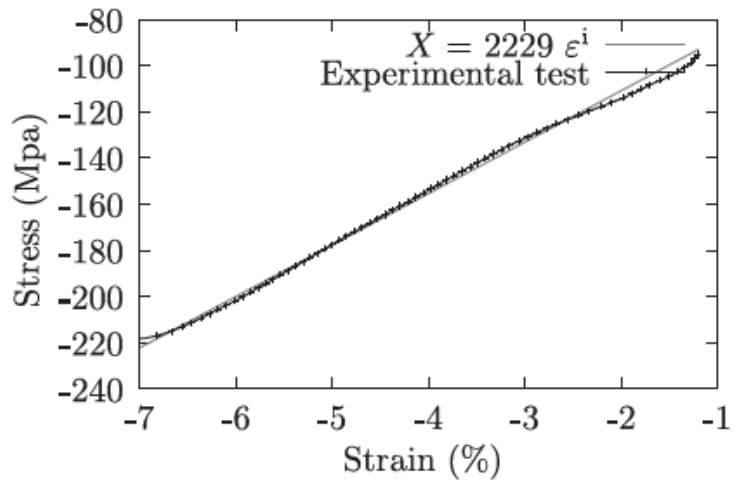

(b)

Fig. 5 - Mechanical characteristics obtained in compression test: (a) Elasticity modulus (MPa), (b) Hardening modulus (Mpa). 


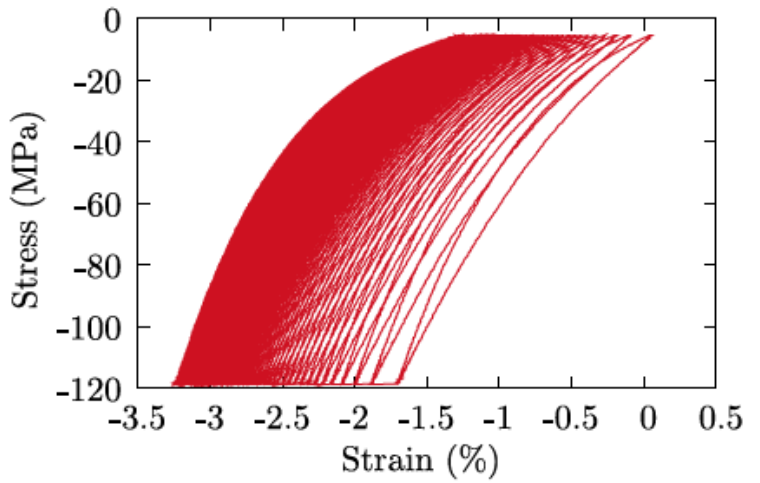

(a)

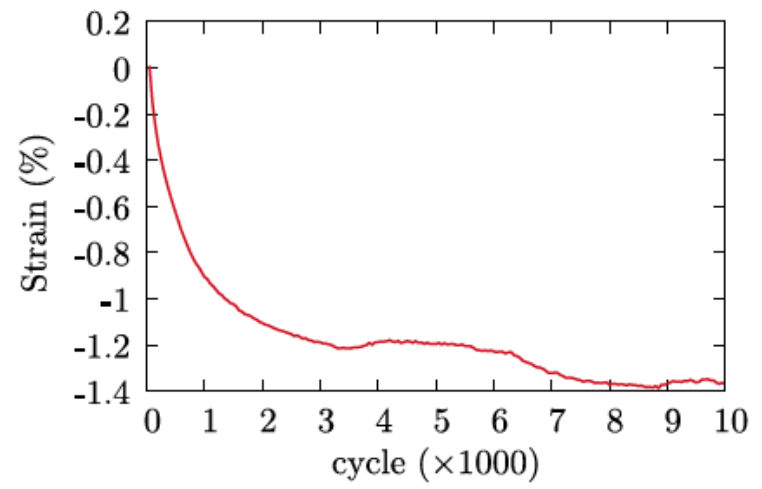

(b)

Fig. 6 - Fatigue test results: (a) Evolution of hysteresis loops under fatigue loading (number of cycles ranging from 5 to 10,000) (b) Total strain amplitude evolution. (A colour version of this figure can be viewed online.)

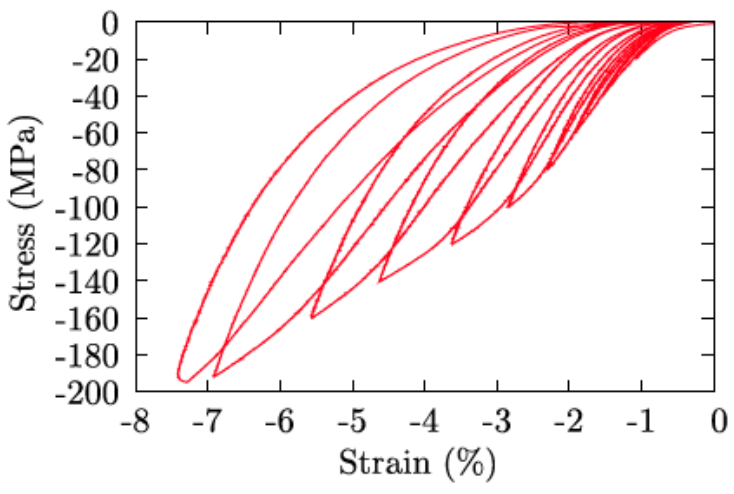

(a)

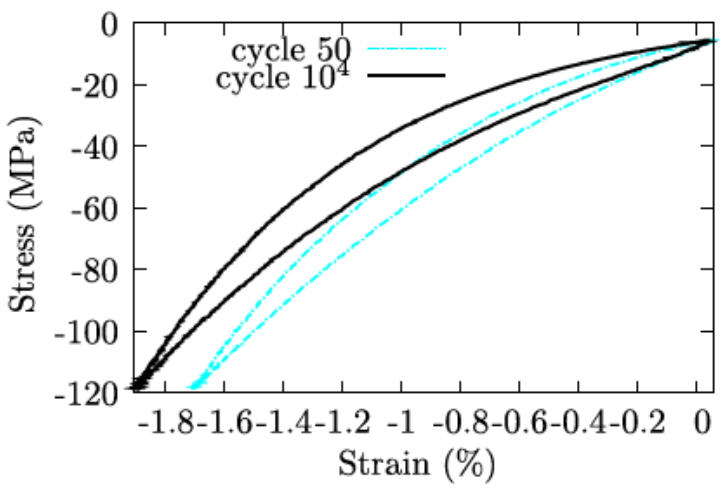

(b)

Fig. 7 - Characterisation of C/C damage by evolution of elasticity: (a) Damage in compression test with loading and unloading, (b) Damage in fatigue test. (A colour version of this figure can be viewed online.)

the 10,000th cycles merged at the beginning of the first cycle. We observe in this figure that the slope of the $10^{4}$ th cycle is lower than the slope of the 50th cycle. This slope decrease corresponds to the loss of stiffness caused by the damage of the material in the elastic range. A complete characterisation of compression of the $\mathrm{C} / \mathrm{C}$ composite must take into account the nonlinearity of the elastic field and damage in the elastic and inelastic domain.

\subsection{Presentation of the indentation test equipment}

The indentation equipment used is a device that allows a con ventional fatigue machine to be adapted in order to be used as a tribometer [14]. This device (DEMAFtrib: DEvice using MA chine Fatigue as TRIBometer) adds a second axis to an usual fatigue machine in the form of an add on accessory. The apparatus can also be used as a fretting wear machine or a fretting fatigue machine.

Fig. 8 shows a schematic diagram of the device. This device is supported by the crosspiece (11) which is attached to the two columns (12) of a standard fatigue machine. The pins (2 3) al low the specimen (1) to be pressed with a perfect symmetry in the form of a pinching motion. The system is composed of lifting beams (89), connecting rods (45) and the actuator (10). The lifting beams (8 9) transform the opening movement of the ram into a pinching movement of the pins on the spec imen. The displacement of the two pins is free according to their axes. The movement of one pin is independent of the movement of the second pin. This freedom of movement with the symmetry of the pedals ( 89 ) and rods (4 5) allows the sys tem be self centred by the specimen.

Normal load is measured by two transducers (6 7). The po sition of these two sensors close to the contact surfaces allows direct measurement of normal load. Effects such as parasitic friction forces in the joints of the system have no effect on the measurement of the normal force. For the tribological con figuration of the device, the specimen (1) is driven by an alter native movement of the fatigue machine actuator.

In the case of an indentation test, the specimen (1) is motionless. The device allows a double indentation of the specimen to be realised. The average depth of indentation va lue $h$ corresponds to half of the measurement given by the extensometer (13).

\section{Mechanical characterisation by indentation test}

Fig. 9(a) represents a typical $\mathrm{P}$ h cycle in an indentation test. The relationship between indentation load $\mathrm{P}$ and the penetra tion $h$ can be defined by Oliver and Pharr [15]: 


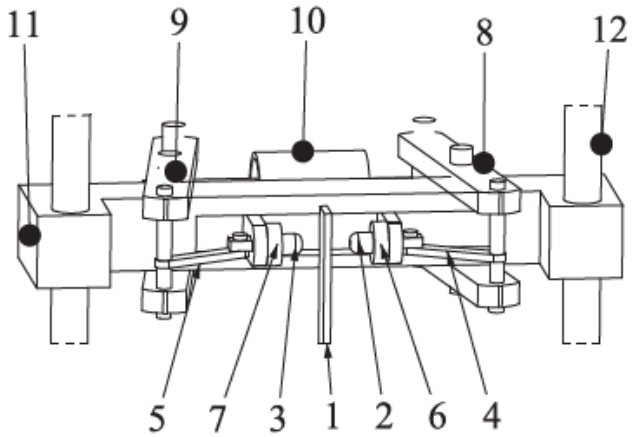

(a)

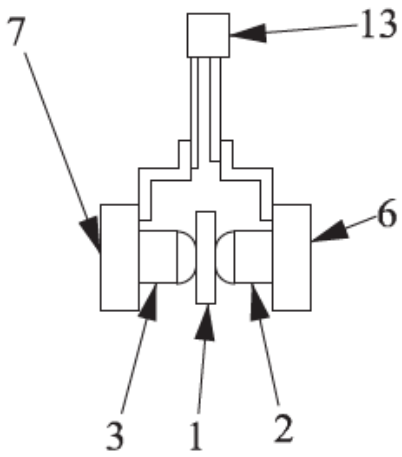

(b)

Fig. 8 - Schematic of the DEMAFtrib: (a): Device in open position, (b) Measurement of indentation depth by extensometer.

$$
\begin{array}{lll}
P & \alpha\left(h \quad h_{\mathrm{f}}\right)^{m}
\end{array}
$$

In the case of weak loads, since no point on the surface of the test specimen exceeds the limit of elasticity, the two curves of loading and unloading are merged. If the contact is of sphere plane type, the indentation cycle can be modelled by the Hertz equation

$P \quad \frac{4}{3} M\left(h \quad h_{f}\right)^{\frac{3}{2}} \sqrt{R}$

with $\mathrm{M}$ the indentation modulus, $\mathrm{h}_{\mathrm{f}}$ the residual depth of the indent, and $R$ the radius of indentation. In the case of an indentation cycle with inelastic behaviour, Eq. (2) is only valid in the unloading curve. The indentation radius is defined by

$$
\frac{1}{\mathrm{R}} \quad \frac{1}{\mathrm{R}_{\mathrm{i}}} \frac{1}{\mathrm{R}_{\mathrm{s}}}
$$

with $R_{i}$ and $R_{S}$ the radii, respectively, of the indenter and the specimen surfaces. The parameter $1 / R_{s}$ is equal to zero for a plane specimen. In the case of an indentation test with sev eral cycles of loading and unloading and an inelastic behav iour of the material, the contact surface of the specimen takes a circular shape and $1 / R_{\mathrm{s}}$ is not equal to zero. The con tact radius $R_{s}$ is calculated in this case using the geometric relationships deduced from Fig. 9 (b):

$R_{\mathrm{s}} \frac{h_{\mathrm{f}}^{2}+a^{2}}{2 h_{\mathrm{f}}}$ by

The parameter $a$ is the radius of the contact area defined

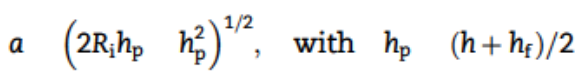

The indentation modulus $M$ is defined by:

$\frac{1}{\mathrm{M}} \quad \frac{1}{\mathrm{M}_{\mathrm{s}}}+\frac{1}{\mathrm{M}_{\mathrm{i}}}$

The parameter $\mathrm{M}_{\mathrm{i}}$ is the indentation modulus of the indenta tor, given by

$M_{\mathrm{i}} \frac{E_{\mathrm{i}}}{1 v_{\mathrm{i}}^{2}}$

with $E_{\mathrm{i}}$ and $v_{\mathrm{i}}$ the Young's modulus and Poisson's ratio of the indenter. The indentation modulus of the specimen depends on the behaviour of the material. For an elastic behaviour, it takes the form:

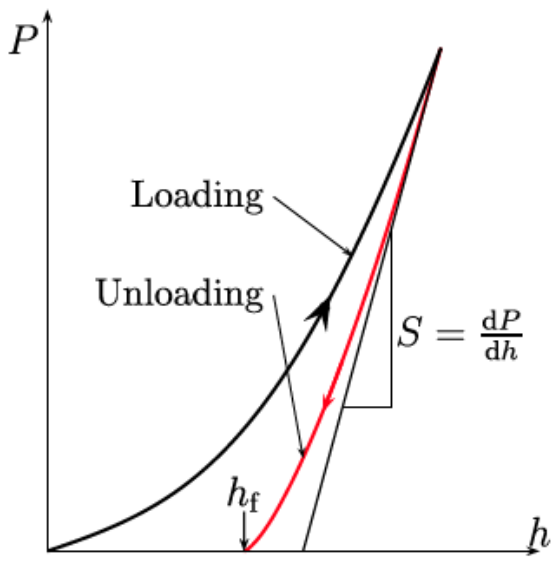

(a)

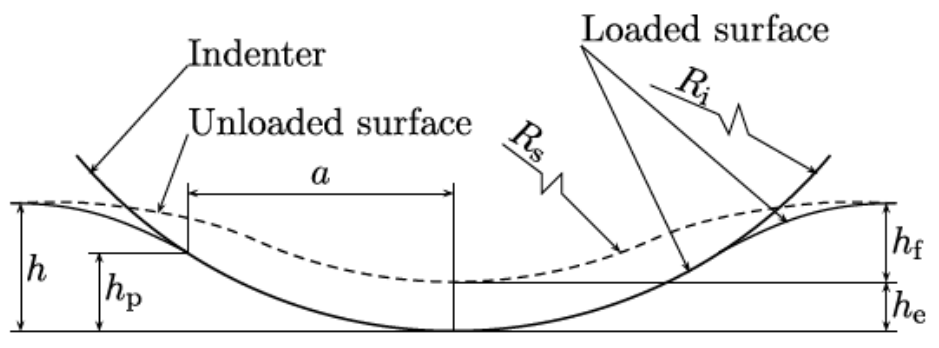

(b)

Fig. 9 - (a) Typical P $\mathrm{h}$ indentation cycle, (b) Geometrical parameters in an indentation test. (A colour version of this figure can be viewed online.) 


$$
M_{s} \frac{c_{1111}^{2} \quad c_{1122}^{2}}{c_{1111}} \frac{E_{s}}{1 \quad v_{s}^{2}}
$$

with $c_{i j k l}$ the coefficients of the stiffness matrix used in the context of Hooke's law $\sigma_{i j} \quad c_{i j k l} \varepsilon_{k l}$.

The heterogeneity of the material in the transverse direc tion is weak and the material is considered to be continuous through the thickness of specimens. The material used in this study is considered as roughly transversely isotropic. In the case of an isotropy in the $(x, y)$ plane, the indentation modulus is expressed by Delafargue and Ulm [16]:

$M_{s} \quad 2 \sqrt{\frac{\gamma^{2}}{c_{11}}}\left(\frac{1}{c_{44}}+\frac{2}{\gamma+c_{13}}\right)^{1}$

with $\gamma \quad \sqrt{ } c_{11} c_{33}$ and $\gamma>c_{13}$. Coefficients $c_{i j}$ are defined in the Hooke's law of a transversely isotropic material:

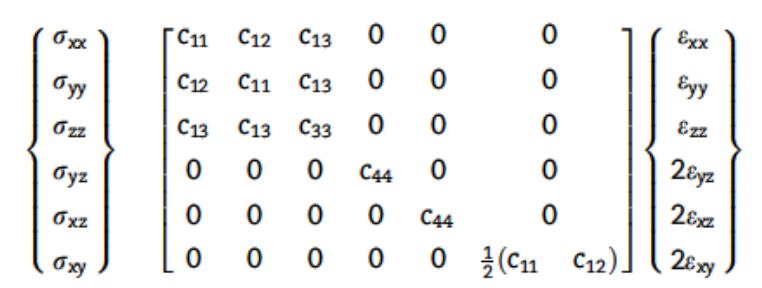

$c_{i j}$ coefficients are determined from Young's modulus $E_{x}$ in the plane of isotropy, Young's modulus $E_{z}$ in the transverse direc tion and Poisson's ratios $v_{z y}, v_{x y}$, hence

$c_{11} \frac{\left(1 n v_{z y}^{2}\right) E_{x}}{A B}, \quad c_{33} \frac{\left(1 n v_{x y}^{2}\right) E_{z}}{A B}, \quad c_{13} \frac{\left(v_{z y}^{2}\right) E_{z}}{B}$

with

$n \frac{E_{x}}{E_{z}}, \quad A \quad 1+v_{x y}$ and $B \quad 1 \quad v_{x y} \quad 2 n v_{z y}^{2}$

The $c_{44}$ coefficient is the shear modulus in the plane $\left(\begin{array}{ll}x & z\end{array}\right)$ or the plane $\left(\begin{array}{ll}y & z\end{array}\right)$. An approximated value of the coefficient $\mathrm{C}_{44}$ can be defined by Nakamura and $\mathrm{Gu}$ [17]:

$$
c_{44} \frac{\left(E_{x}+E_{z}\right) / 2}{2\left(1+\left(v_{x z}+v_{z x}\right) / 2\right)}
$$

The objective of the study is to identify the mechanical properties in the transverse direction only. The mechanical properties in the plane of isotropy are found in the literature. Young's modulus in the plane of isotropy $E_{x} \quad 37.61 \mathrm{GPa}$ is identified in Fig. 10 from a tensile test realised by Douarche et al. [2]. As far as the Poisson's coefficients is concerned, the two values $v_{x y} \quad 0.25$ and $v_{z y} \quad 0.11$ are taken from litera ture $[18,19]$.

The indentation modulus $\mathrm{M}$ is identified in the indentation test from the Hertz equation using the method of Field [20]. Transverse Young's modulus $E_{z}$ is obtained from Eqs. (9) and (11). The shear modulus is obtained by Eq. (12) after calculat ing Young's modulus $E_{z}$.

To identify the mechanical characteristics in the inelastic field, the law of Hertz (Eq. (2)) is expressed as [21,22]:

$\sigma \quad M \varepsilon, \quad$ with $\sigma \quad \frac{P}{\pi a^{2}} \quad$ and $\varepsilon \quad \frac{4}{3 \pi} \frac{h}{a}$

In the case of inelastic behaviour, the specimen indenta tion modulus $M_{s}^{i}$ is defined as a function of the hardening modulus $\mathrm{H}_{z z}$ in the transverse direction and $\mathrm{H}_{x x}$ in the plane of isotropy

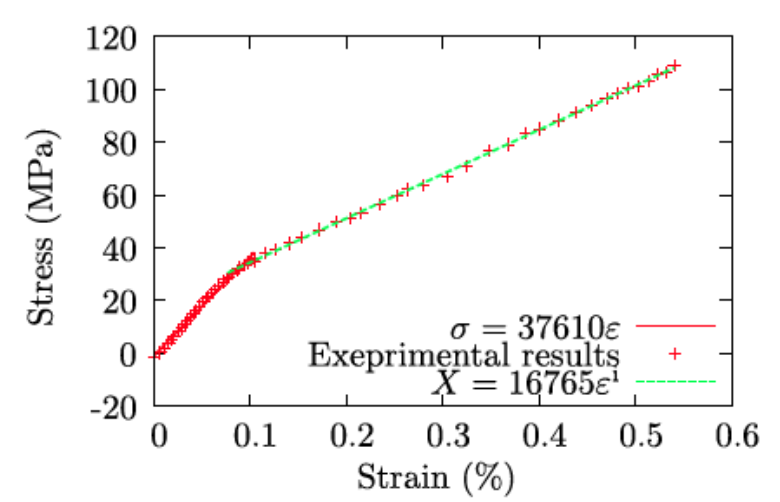

Fig. 10 - Tensile strain/stress curve in the plan of isotropy taken from Douarche et al. work [2]. (A colour version of this figure can be viewed online.)

$\mathrm{M}_{\mathrm{s}}^{\mathrm{i}} \quad \sqrt{2 \mathrm{H}_{\mathrm{zz}}} \frac{\mathrm{DF}}{\mathrm{D}+\mathrm{F}}$

with $D \quad H_{z z}+H_{x x}$ and $F \quad \sqrt{ } H_{z z} H_{x x}$. This equation is a modi fied version of Eq. 9, as obtained by neglecting the elastic deformations in the inelastic field.

Other parameters such as the Brinell hardness, the maxi mal resistance and the damage of the material could be iden tified. The realisation of an indentation test allows access to the value of the Brinell hardness using the Brinell relationship

$H_{B} \frac{P}{2 g \pi R_{i}^{2}\left(1 \quad \sqrt{1} \quad\left(a / R_{i}\right)^{2}\right)}$

with $a$ the contact radius calculated by the geometric rela tionship (5) and $g$ the gravitational constant. The calculation of the Brinell hardness provides the value of the transverse maximal resistance using relation of the type:

$\mathrm{Rm}_{\mathrm{z}} \quad \mathrm{CH}_{\mathrm{B}}$

with $\mathrm{c}$ a constant of the material.

\subsection{Methodology of the test}

A brake disc having a thickness of $5 \mathrm{~mm}$ is polished with suc cessively finer media and cut into $20 \times 20 \mathrm{~mm}^{2}$ samples. A specimen consists of two glued samples on a metal substrate as shown in Fig. 11. The metallic substrate is fixed to the hydraulic grip of the fatigue machine. The material of the

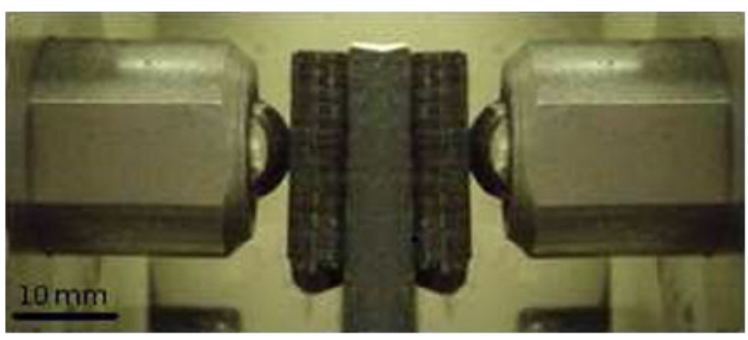

Fig. 11 - Image of the specimen composed of $2 \mathrm{C} / \mathrm{C}$ composite samples glued on a metallic substrate. (A colour version of this figure can be viewed online.) 
indenter is $100 \mathrm{C} 6$ steel and the diameter of the indenter spheres is $12 \mathrm{~mm}$.

The extensometer used for the indentation measurement is attached to the ball carrier shown in Fig. 11. The control of the test can be done either by indentation depth $h$ or inden tation load P using a feedback loop.

Four indentation tests were performed on four specimens. Each test consisted of five load steps, $100 \mathrm{~N}$ to $500 \mathrm{~N}$, with an increment of $100 \mathrm{~N}$ for each step. The loading is applied with load rate of $1.5 \mathrm{Ns}^{-1}$ and the unloading is controlled by inden tation depth $h$ with a speed of $0.1 .10^{2} \mathrm{~mm} . \mathrm{s}^{1}$.

\subsection{Indentation results}

Fig. 12(a) shows a representative cycle obtained during the indentation tests. One can see that for each cycle, the load ing curve is different from that of the unloading proving that the material becomes inelastic at small loads. Each indenta tion cycle can be modelled by the theoretical cycle presented in Fig. 12(b). The loading cycle can be decomposed into two mechanisms The first mechanism represents the case where the volume under the contact surface is not completely inelastic. The second mechanism corresponds to the case where the entire volume under the surface of contact sur face is inelastic. Owing to the nonlinearity of the material, curves corresponding to the first mechanisms are not merged. However, a continuity of the second mechanisms is observed on the loading curves. The final loading point of each cycle, corresponding to the end of the second mech anism for this cycle, represents the elasticity limit for the next cycle. This is characteristic of the hardening phenome non. Indeed all of the second mechanisms of indentation cy cles can be fitted with one major curve representing the material hardening. From a qualitative point of view, a sim ilarity is observed between the loading unloading cycles in a compression test (Fig. 7 (a)) and in an indentation test (Fig. 12).

The indentation radius is inferred from the indentation depth using Eq. (5). The values of the radii of contact area are, respectively from the first to the fifth cycle: 280,390 , $477,542,592 \mu \mathrm{m}$. From the second cycle, the contact area is larger to the maximum thickness of a bundle of fibres as discussed in Section 2.1. We supose that from the second cy cle, the indented volume is representative of a homogeneous volume of the composite. Hence, the characterisation of the material is made for a load greater than $100 \mathrm{~N}$.

Fig. 13(a) shows five unloading curves of indentation cycle. With each experimental curve, the fitted curve of the Hertz law (Eq. (2)) is presented. Overall a good match between experimental cycles and modelled cycles by the Hertz law is observed. However, a small dispersion is observed at low loads. This dispersion is due to the non linearity of the mate rial in the elastic range. Fig. 13(b) shows the unloading cycles obtained by Hertz law $P \quad \frac{4}{3} M(h)^{\frac{3}{2}} \sqrt{ } R$ without the residual in dent depth $h_{\mathrm{f}}$. A continued decrease of the indentation mod ulus is observed with the cycle order in this figure. The decrease in the indentation modulus, and the related Young's modulus, is due to the material damage induced by the load ing unloading cycles. Similar trends are observed in the curve of Fig. 7 (b) for the fatigue test.

The indentation modulus and hence the transverse Young's modulus $E_{\mathrm{z}}$ is determined from the cycles found in Fig. 13(a). An average indentation modulus $\mathrm{M}_{\mathrm{s}} \quad 18.61 \mathrm{GPa}$ is determined from these results using Eq. (6) considering a Young's modulus $E_{\mathrm{i}} \quad 210 \mathrm{GPa}$ and Poisson's ratio $v_{\mathrm{i}} \quad 0.3$ for the indenter. A transverse Young's modulus of $E_{z} \quad 10.33 \mathrm{GPa}$ is obtained after the numerical solution of Eq. (9) using Maple soft. This value is very close to the value obtained from the compression test shown in Fig. 5(a).

Yield stress and the hardening modulus in transverse direction are determined from indentation stress/strain cy cles given by Eq. (13) and presented in Fig. 14. The elasticity limit is expressed as a function of the value $\sigma_{0}$ corresponding to the beginning of the second mechanism:

$\sigma_{0} \quad c R_{z}$

with $c$ a material constant. Eq. (17) is similar to the equation used in the literature to calculate the elasticity limit function of the hardness of Mayer [23,24]. The beginning of the second mechanism corresponds to a value of $300 \mathrm{MPa}$ at $\varepsilon \quad 1 \%$ for the second cycle. Taking a constant c 3 , one can deduce a value of transverse yield limit $R_{z} 100 \mathrm{MPa}$. This value is

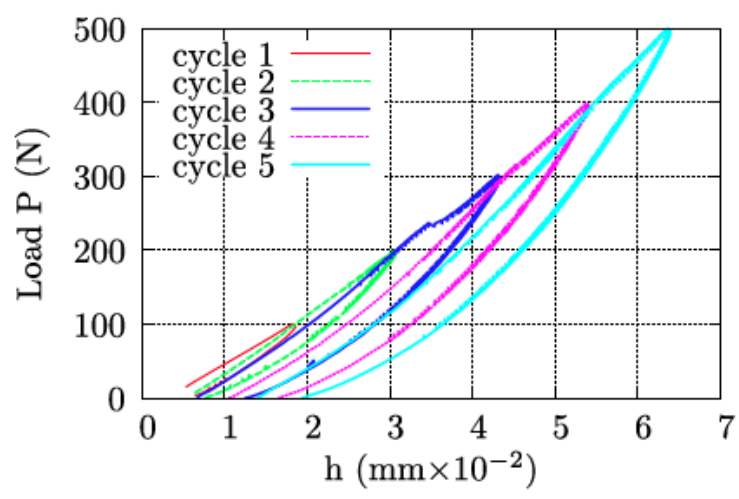

(a)

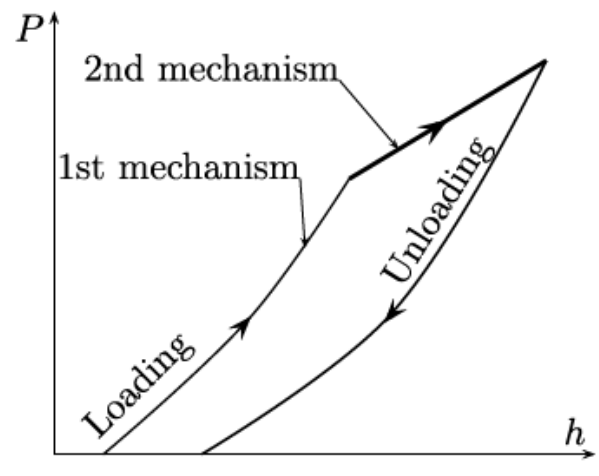

(b)

Fig. 12 - Experimental indentation cycles: (a) Experimental cycle with loading-unloading, (b) Typical indentation cycle. (A colour version of this figure can be viewed online.) 


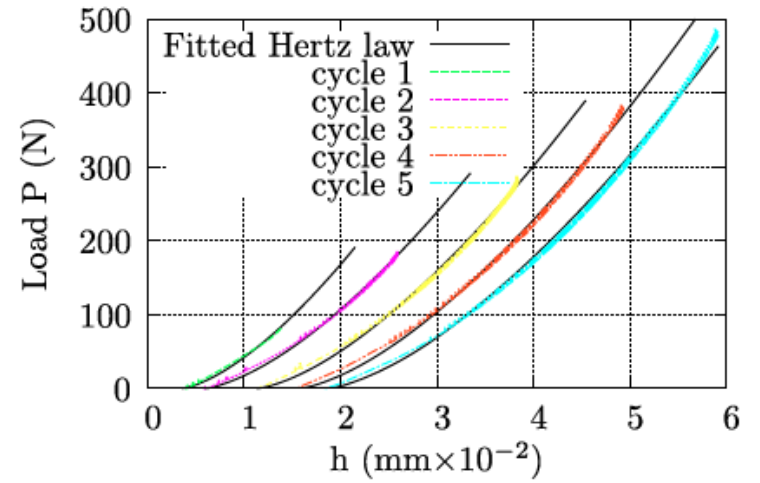

(a)

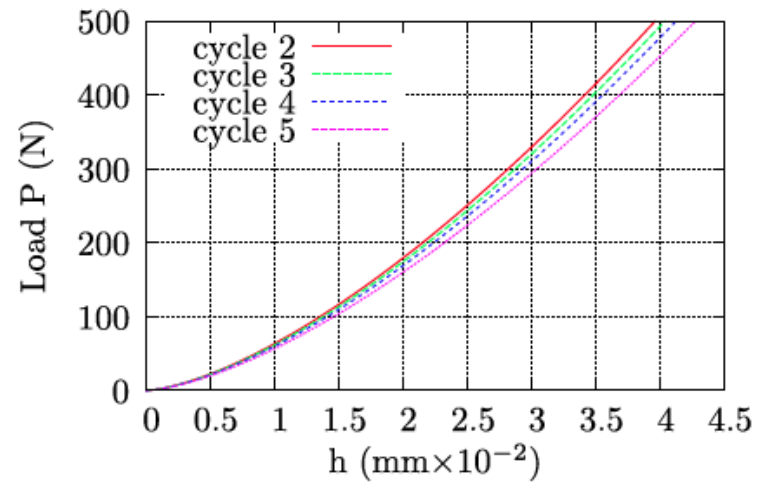

(b)

Fig. 13 - Unloading curves of indentation cycles: (a) Experimental curve and fitted Hertz law (Eq. (2)), (b Fitted Hertz law without $h_{f}$, hence: $P \quad \frac{4}{3} M(h)^{\frac{3}{2}} \sqrt{ } R$. (A colour version of this figure can be viewed online.)

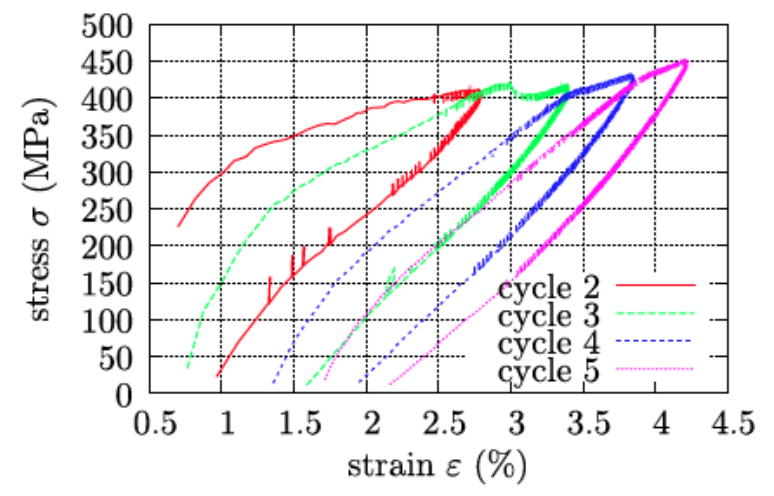

Fig. 14 - Indentation cycles expressed in strain/stress form (Eq. (13)). (A colour version of this figure can be viewed online.)

not far from the value determined in the compression test and presented in Fig. 4.

The inelastic indentation modulus is determined from the second part of loading curves. It corresponds to the slope of the second mechanism segment. A medium indentation inelastic modulus of $\mathrm{M}_{\mathrm{s}} \quad 4.6 \mathrm{GPa}$ is determined from the sec ond mechanism of loading cycles. This allows the transverse indentation modulus $\mathrm{H}_{\mathrm{zz}} \quad 3.2 \mathrm{GPa}$ to be calculated from Eq. (14) taking into account the hardening modulus in the isotropic plane $\mathrm{H}_{x x} \quad 16.7 \mathrm{GPa}$ determined from the results of Douarche et al. (Fig. 10).

\section{Numerical validation}

\subsection{Choice of behaviour model}

The chosen model is based on the separation between the elastic and inelastic strains [25]:

$\varepsilon \quad \varepsilon^{\mathrm{e}}+\varepsilon^{\mathrm{i}}$

Elastic strains are related to the stresses by the generalised Hooke's law $\varepsilon^{\mathrm{e}} \quad C^{1}: \sigma$. The field of elasticity is defined by the yield surface function $f(\sigma, X)$ with $X$ the hardening variables. To simulate the case of loads and unloads, the field of elasticity is defined also by $\dot{f}(\sigma, X)$ in such a way that:

- elastic behaviour

$f(\sigma, X)<0$ or $(f(\sigma, X) \quad 0$ and $\dot{f}(\sigma, X)<0) \rightarrow \varepsilon \quad \varepsilon_{\mathrm{e}}$ $C^{1}: \sigma$

- inelastic behaviour

$f(\sigma, X) \quad 0$ and $\dot{f}(\sigma, X) \quad 0 \rightarrow \varepsilon \quad C^{1}: \sigma+\varepsilon^{i}$

The inelastic strains are defined by the rule of normality:

$\varepsilon^{i} \quad \lambda \frac{\partial f}{\partial \sigma}$

The parameter $\lambda$ is a positive scalar defined from the consis tency condition $\dot{f}(\sigma, X) \quad 0$.

As was presented in Section 2.1, the hardening of the C/C material corresponds to the evolution of cracks at different scales and the debonding of fibres with the matrix. The hard ening depends then on the direction of loading and it is prin cipally of a kinematic kind. The hardening, quasi linear, shown in Figs. 4 and 5(b), as well as the envelope curve of the inelastic field of the load unload compression test (Fig. 7(a) allow a choice of Prager type hardening for plastic materials:

X $\quad H: \varepsilon^{\mathrm{i}}$

The tensor $\mathrm{H}$ is a tensor of order four. Numerically this tensor corresponds to a diagonal matrix whose diagonal elements correspond to the six hardening coefficients of the material.

Hill's criterion is used as a yield surface

f $\left(3 / 2(S \quad X): N:\left(\begin{array}{lll}S & X\end{array}\right)\right)^{\frac{1}{2}} \quad R_{0}$

with $S$ the deviator of stresses defined by $S_{i j} \quad \sigma_{i j} \quad \frac{1}{3} \operatorname{tr}\left(\sigma_{i j}\right)$ and $\mathrm{N}$ the matrix of Hill criterion defined later in Eq. (26). The mul tiplier parameter $\lambda$ can be deduced from the consistence con dition $\dot{f}(\sigma, \mathrm{X}) \quad 0$, hence [25]:

$\lambda \quad \varepsilon^{\mathrm{i}}: \mathrm{N}^{1}: \varepsilon^{\mathrm{i}}$

Taking into account the load function (Eq. (23)), the flow rule (21) takes the form 
Table 1 - The identified coefficients used in the numerical validation.

\begin{tabular}{llllllllll} 
Coefficient & $R_{0}$ & $N_{x x}$ & $N_{z z}$ & $N_{z x}$ & $N_{x y}$ & $H_{x x}$ & $H_{z z}$ & $H_{z x}$ & $H_{x y}$ \\
\hline Value & $72 \mathrm{MPa}$ & 8.36 & 3.20 & 4.1 & 9.0 & $11.2 \mathrm{MPa}$ & $2.6 \mathrm{MPa}$ & $2.3 \mathrm{MPa}$ & $5.6 \mathrm{MPa}$ \\
\hline
\end{tabular}

$\varepsilon^{\mathrm{i}} \quad \lambda \frac{\mathrm{N}:(\sigma \quad \mathrm{X})}{\|\sigma \quad \mathrm{X}\|_{\mathrm{N}}}$

with $\|\sigma \quad X\|_{N} \quad\left(3 / 2\left(\begin{array}{ll}S & X\end{array}\right): N:\left(\begin{array}{ll}S & X\end{array}\right)\right)^{\frac{1}{2}}$. The $N$ matrix is a diagonal matrix defined by:

$\left[\begin{array}{ccccccc}2 e & g+2 h & 0 & 0 & 0 & 0 & 0 \\ 0 & 2 e+2 g & h & 0 & 0 & 0 & 0 \\ 0 & 0 & e+2 g+2 h & 0 & 0 & 0 \\ 0 & 0 & 0 & 2 l & 0 & 0 \\ 0 & 0 & 0 & 0 & 2 m & 0 \\ 0 & 0 & 0 & 0 & 0 & 2 n\end{array}\right]$

Coefficients $e, g, h, l, m$ and $n$ are defined from the limits of elasticity along the axes. For the material of this study, with a transverse isotropy around the $\mathrm{z}$ axis

e $\frac{1}{2}\left[2\left(\frac{R_{0}}{R_{y}}\right)^{2} \quad\left(\frac{R_{0}}{R_{z}}\right)^{2}\right]$

h $g \frac{1}{2}\left(\frac{R_{0}}{R_{z}}\right)^{2}$

$l \quad m\left(\frac{R_{0}}{\tau_{y z}}\right)^{2}$

$n \quad\left(\frac{R_{0}}{\tau_{x y}}\right)^{2}$

with $R_{0}$ a reference of the elasticity limit, $R_{x}$ and $R_{z}$ are, respectively, the limits of elasticity in the plane of isotropy and in the transverse direction. The coefficients $\tau_{x y}$ and $\tau_{y z}$ are the shear limits, respectively, in the isotropic plane and in the transverse plane. The model used is part of the zéBu loN finite element code $[26,27]$.

\subsection{Model identification}

The identification of the parameters $E_{z}, R_{z}$ and $H_{z z}$ obtained directly from the indentation test are presented in Section 3.2. The reference of elasticity limit $R_{0}$ is chosen equal to $\left(R_{z}+R_{x}\right) / 2$. The elasticity limit in the isotropic plane $R_{x} \quad R_{y} 35 \mathrm{MPa}$ is identified in Fig. 10 from Douarche's work [2] on the same material. Taking inspiration from the von Mises criterion, the shear resistance in the isotropic plane is defined by Yonezu et al. [28] $\tau_{x y} \quad R_{y} / \sqrt{ } 3$ and the shear resis tance in a transverse plane is defined by $\tau_{z y} \tau_{x y} \sqrt{\frac{R_{z}}{R_{y}}}$. The shear hardening modulus in the isotropic plane $(x, y)$ and in a transverse plane are calculated similarly to the shear mod ulus calculation:

$H_{x y} \frac{H_{z z}}{2\left(1+v_{p}\right)}$ and $H_{z x} \frac{H_{z z}+H_{x x}}{4\left(1+v_{p}\right)}$

Neglecting the elastic strains in the inelastic field and in order to respect the incompressibility of the material in the inelastic domain, Poisson's ratio $v_{p}$ is chosen equal to 0.5 .

To put the parameter $2 / 3$ in factor in the load function (23), the hardening coefficients $H_{i j}$ are divided by 1.5. The set of model parameters in the inelastic domain are presented in Table 1.

\subsection{Finite element model}

The ball and the specimen are modelled using the ZéBuloN finite element code. The set is discretised by 3437 axisymmet ric elements with linear interpolation and 8655 nodes hence a
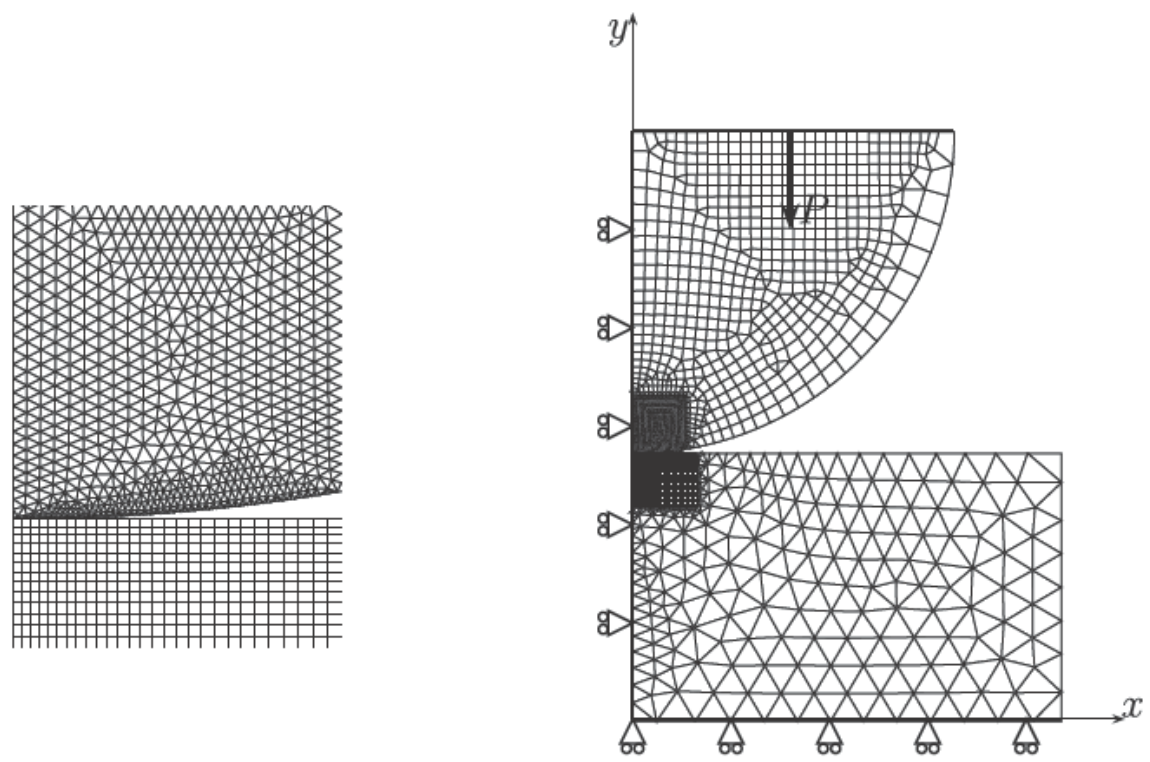

Fig. 15 - Mesh and boundary conditions with a zoom on contact zone. 


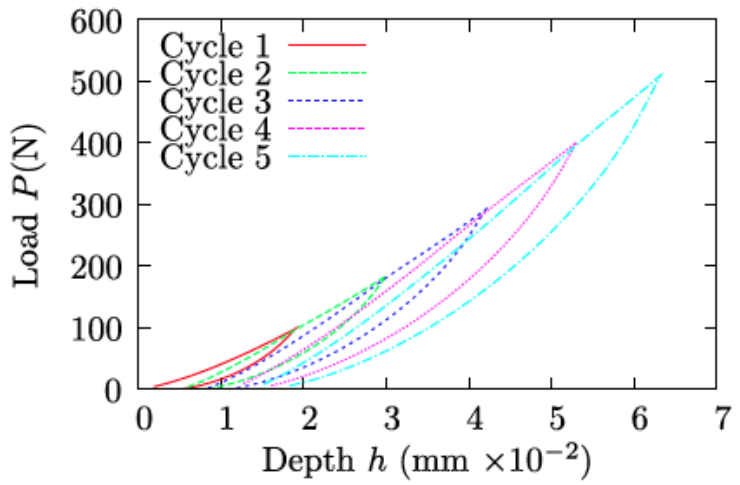

Fig. 16 - Indentation cycles obtained by FEM. (A colour version of this figure can be viewed online.)

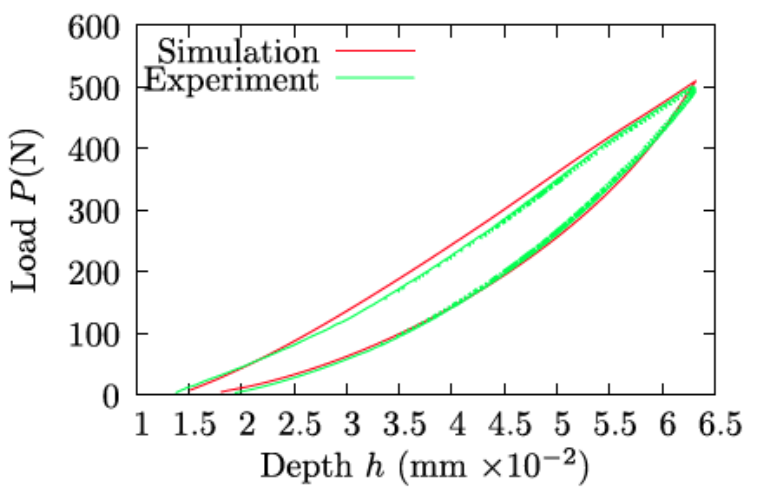

Fig. 17 - The fifth cycle obtained by experiment and by FEM. (A colour version of this figure can be viewed online.)

17,310 degrees of freedom (DOF) for the problem. Fig. 15 pre sents the mesh used with a zoom on the contact area. The load is applied to the upper part of the ball in displacement form. The bottom side of the specimen is blocked in the vertical direction. The vertical axis is blocked in the radial direction implicitly owing to the axisymmetry of the model (see Fig. 15). The material model used is described in Section 4.1.

Fig. 16 presents the indentation cycles obtained by finite element method (FEM). From a qualitative point of view, a similarity between these cycles and those obtained experi mentally (see Fig. 12) is observed.

For a comparison in the quantitative point of view be tween numerical and experimental results, Fig. 17 presents the last cycle of testing (cycle 5) obtained by the two methods. This curve shows, globally, a good match between numerical and experimental cycles.

Fig. 18 shows the equivalent inelastic strain isovalues

$\varepsilon_{\text {eq }}^{i} \quad\left(3 / 2 \varepsilon_{i j}^{i}: \varepsilon_{i j}^{i}\right)^{1 / 2}$

for the 5 th cycle. Fig. 18(a) presents the $\varepsilon_{\mathrm{eq}}^{\mathrm{i}}$ isovalues at the beginning of the cycle (at no load) and 18(b) the isovalues at the maximal loading $(P 500 N)$. These evolutions show that at the beginning of the indentation cycle, the indented area is not completely inelastic. Unlike the case of indentation at maximum load, the indented volume is completely inelastic. This change in the indented volume explains the two mecha nisms that can be seen in the loading cycles. Hence, identifi cation of the hardening modulus must be carried out close to maximum load.

Fig. 19 shows the permanent profile $h_{f}(r)$ of the contact surfaces at the end of each cycle. These profiles show that the contact surface is no longer flat after each indentation cy cle. The deformation of the contact surfaces in the calculation of the contact radius (Eq. (4)) must be taken into account.

One considers in this study a sampled volume (SV) of spec imen material by the presented indentation technique as the deformed volume of this specimen. As a criterion of deforma tion, the equivalent strain $\varepsilon_{\mathrm{eq}} \quad\left(3 / 2 \varepsilon_{i j}: \varepsilon_{i j}\right)^{1 / 2}$ is utilized to de fine the limit of this volume. The Figs. 20 and 21 present the evolution of $\varepsilon_{\text {eq }}$ according to the radius and the depth of the

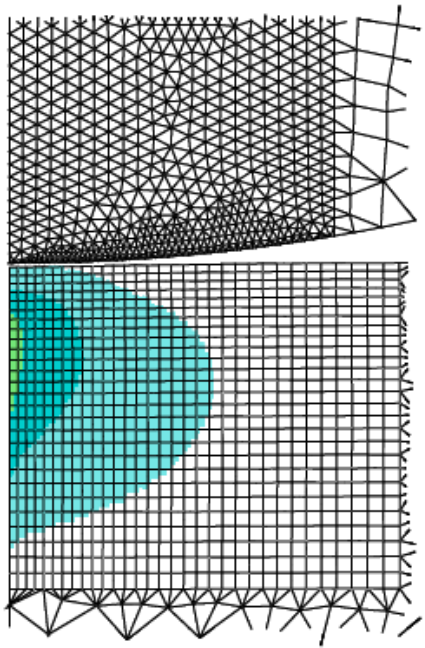

(a)

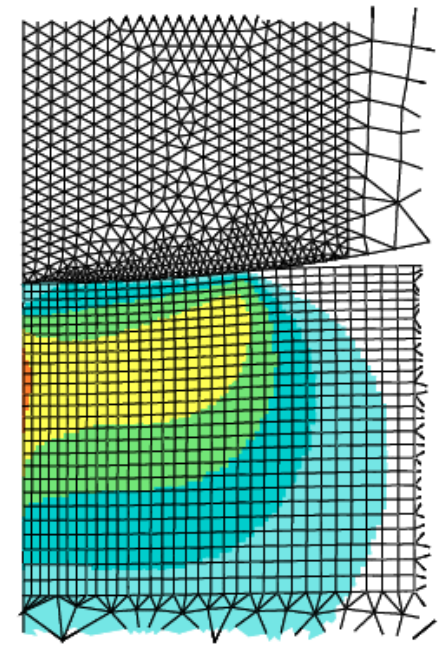

(b)
8.

7.

6.

5.

4.

3.

2 .

1.

(c)

Fig. 18 - Evolution of the $\varepsilon_{\mathrm{eq}}^{i} \quad\left(3 / 2 \varepsilon_{\mathrm{ij}}^{i}: \varepsilon_{\mathrm{ij}}^{\mathrm{i}}\right)^{1 / 2}$ equivalent train for the 5 th cycle: (a) $\varepsilon_{\mathrm{eq}}^{i}$ at the beginning of the cycle, (b) $\varepsilon_{\mathrm{eq}}^{i}$ at the maximum load of the cycle, (c) Scale values in (\%) for the two simulations. (A colour version of this figure can be viewed online.) 


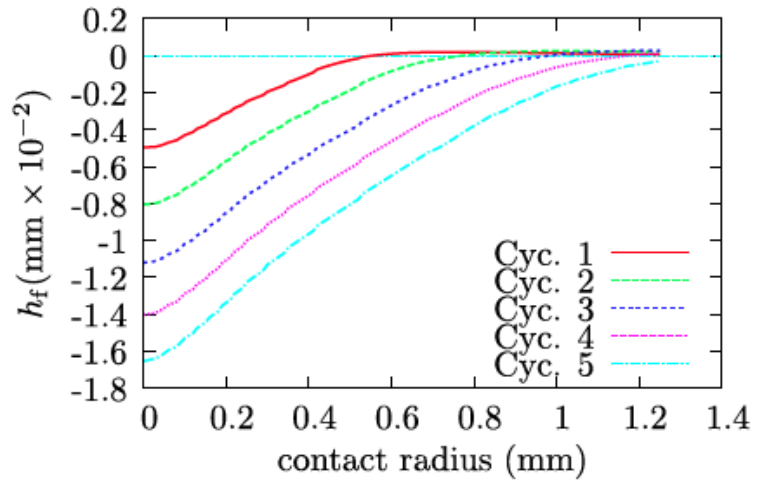

Fig. 19 - Evolution of the residual depth $h_{f}(r)$ for the five cycles. (A colour version of this figure can be viewed online.)

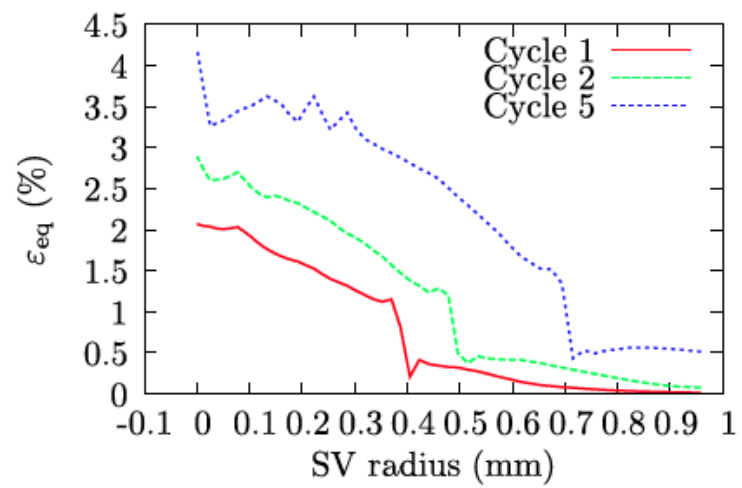

Fig. 20 - Evolution of the equivalent strain $\varepsilon_{\mathrm{eq}} \quad\left(3 / 2 \varepsilon_{i j}: \varepsilon_{i j}\right)^{1 / 2}$ according to the radius of the sampled volume (SV). (A colour version of this figure can be viewed online.)

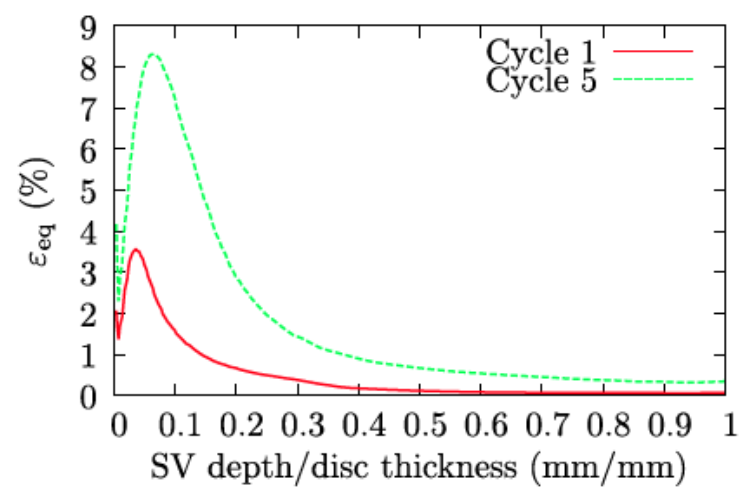

Fig. 21 - Evolution of the equivalent strain $\varepsilon_{e q} \quad\left(3 / 2 \varepsilon_{i j}: \varepsilon_{i j}\right)^{1 / 2}$ according to the ratio between depth of the sampled volume (SV) and the disc thickness. (A colour version of this figure can be viewed online.)

deformed volume. One can observe in Fig. 21 that from the first cycle, the deformed depth of the SV is equal to $40 \%$ of the disc thickness, which corresponds to a height of $2 \mathrm{~mm}$ and a SV of an average of five plies of the specimen. We can also observe in Fig. 20 that, from the second cycle, the contact radius approaches the value of $1 \mathrm{~mm}$. Therefore, the smallest
SV obtained from the second indentation cycle is a cylinder of dimensions $(\pi \times 2) \mathrm{mm}^{3}$ which could be considered as a repre sentative volume of the material composite and not a compo nent only.

\section{Conclusion}

In this paper, a double indentation technique with a spherical indenter is used for the mechanical characterisation of $\mathrm{C} / \mathrm{C}$ composites. The characterisation of the material in the elastic range is identified in the unloading cycle by fitting the Hertz law. The elastic modulus of the indentation may also be iden tified by the calculation of the stiffness at the start of unload ing (see Fig. 9(a)):

$S \quad \frac{d P}{d h} \quad 2 M\left(h \quad h_{f}\right)^{\frac{1}{2}} \sqrt{ } R$

In this study, both methods gave approximately the same results, but only the results obtained by the first method are presented. The anisotropy of the material is taken into ac count in elastic and inelastic domains. The results obtained confirm that the proposed technique can be used to identify the mechanical characteristics in the elastic field tacking into consideration the anisotropy of the material.

The preliminary study on the compression and fatigue of $\mathrm{C} / \mathrm{C}$ composites with the analysis of their miscrostructure al lowed a material model with elastic and inelastic behaviour to be chosen. The results showed that kinematic hardening can be used to model the inelasticity of these materials. The inelastic parameters with a transverse isotropy of the chosen model are identified by the proposed indentation technique.

In parallel to the experimental study, a numerical study simulating the indentation of the composite by the finite ele ments method is conducted. The chosen model is based on the elastoplasticity of the metallic materials. The Hill crite rion is chosen as a loading surface with kinematic hardening. The model parameters of the material in the transverse direc tion are identified from the indentation test. The parameters in the plane of isotropy are recovered from the literature deal ing with the same material. The results obtained show, over all, a good correspondence between the simulation and the experimental study.

In this study the material damage is not taken into consid eration for sake of simplicity. Indeed, the damage can easily be characterised by the developed technique after identifying the loss of rigidity shown in Fig. 13(b) curve. Once the material damage characterised, the model can be ameliorated by inte grating the concept of the effective stress presented by $\mathrm{M}$. Cheikh in [29]. This study shows that a simple technique such as spherical indentation can be used to characterise through thickness properties of the $\mathrm{C} / \mathrm{C}$ composite.

\section{Acknowledgements}

This study is sponsored by Ratier Figeac and Conseil Régional Midi Pyrénée (CRMiP). The authors wish to thank M. Malvy President of CRMiP for his support to the growth of research activities at the Figeac IUT and E. Delbos, E. Pluchon (Ratier Figeac) for the helpful discussions and granting permission to publication. The authors are grateful to A. Fermy (IUT 
Figeac) and S. Tovar (EMAC Albi) for the manufacturing and the preparation of the specimens used in the experimental section of this work.

R E F E R E N C E S

[1] Davies IJ, Rawlings RD. Mechanical properties in compression of low density carbon/carbon composites. Composites 1994;25(3):229 36

[2] Douarche N, Rouby D, Peix G, Jouin JM. Relations between x ray tomography, density and mechanical properties in carbon carbon composites. Carbon 2001;39(10):1455 65

[3] Ozcan S, Tezcan J, Filip P. Microstructure and elastic properties of individual components of c/c composites. Carbon 2009;47(15):3403 14.

[4] Iwashita N, Swain MV, Field JS, Ohta N, Bitoh S. Elasto plastic deformation of glass like carbons heat treated at different temperatures. Carbon 2001;39(10):1525 32.

[5] Field JS, Swain MV. The indentation characterisation of the mechanical properties of various carbon materials: glassy carbon, coke and pyrolytic graphite. Carbon 1996;34(11):1357 66

[6] Kanari M, Tanaka K, Baba S, Eto M. Nanoindentation behavior of a two dimensional carbon carbon composite for nuclear applications. Carbon 1997;35(10 11):1429 37.

[7] Diss P, Lamon J, Carpentier L, Loubet J, Kapsa P. Sharp indentation behavior of carbon/carbon composites and varieties of carbon. Carbon 2002;40(14):2567 79.

[8] Marx D, Riester L. Mechanical properties of carbon carbon composite components determined using nanoindentation. Carbon 1999;37(11):1679 84.

[9] Siron O, Lamon J. Damage and failure mechanisms of a3 directional carbon/carbon composite under uniaxial tensile and shear loads. Acta Mater 1998;46(18):6631 43.

[10] Siron O, Pailhes J, Lamon J. Modelling of the stress/strain behaviour of a carbon/carbon composite with a 2.5 dimensional fibre architecture under tensile and shear loads at room temperature. Compos Sci Technol 1999;59(1):1 12

[11] Pailhes J, Camus G, Lamon J. A constitutive model for the mechanical behavior of a 3d c/c composite. Mech Mater 2002;34(3):161 77

[12] Fantozzi G, Reynaud P. Mechanical hysteresis in ceramic matrix composites. Mater Sci Eng A 2009;521 522:18 23.

[13] Hou X, Liu X, Xu J, Shen J, Liu X. A self optimizing electrodeposition process for fabrication of calcium phosphate coatings. Mater Lett 2001;50(2 3):103 7.

[14] Cheikh M, Fermy A. Versatile device research of mechanical properties of a specimen; 2012. Patent FR20110051436.
[15] Oliver WC, Pharr GM. Measurement of hardness and elastic modulus by instrumented indentation: advances in understanding and refinements to methodology. J Mater Res 2004;19:3 20.

[16] Delafargue A, Ulm FJ. Explicit approximations of the indentation modulus of elastically orthotropic solids for conical indenters. Int J Solids Struct 2004;41(26):7351 60.

[17] Nakamura T, Gu Y. Identification of elastic plastic anisotropic parameters using instrumented indentation and inverse analysis. Mech Mater 2007;39(4):340 56.

[18] Riccotti Y, Douarche N, Franciosi P, Rouby D. Estimation des modules d'élasticité d'un stratifié carbone carbone en présence de dégradation des interfaces fibres matrice. In: Matériaux 2002. Tours, France; 2002.

[19] Rao MV, Mahajan P, Mittal RK. Effect of architecture on mechanical properties of carbon/carbon composites. Compos Struct 2008;83(2):131 42.

[20] Field JS, Swain MV. A simple predictive model for spherical indentation. J Mater Res 1993;8:297 306.

[21] Kalidindi S, Pathak S. Determination of the effective zero point and the extraction of spherical nanoindentation stress strain curves. Acta Mater 2008;56(14):3523 32

[22] Donohue BR, Ambrus A, Kalidindi SR. Critical evaluation of the indentation data analyses methods for the extraction of isotropic uniaxial mechanical properties using finite element models. Acta Mater 2012;60(9):3943 52.

[23] Sakai M. The meyer hardness: a measure for plasticity? J Mater Res 1999;14:3630 9.

[24] Mukhopadhyay NK, Paufler P. Micro and nanoindentation techniques for mechanical characterisation of materials. Int Mater Rev 2006;51(4):209 45

[25] Chaboche JL. Thermodynamic formulation of constitutive equations and application to the viscoplasticity and viscoelasticity of metals and polymers. Int J Solids Struct 1997;34(18):2239 54.

[26] Besson J, Le Riche R, Foerch R, Cailletaud G. Object oriented programming applied to the finite element method. Part II: application to material behaviors. REEF 1998;7(5):567 88.

[27] Besson J, Le Riche R, Foerch R, Cailletaud G. Object oriented programming applied to the finite element method. Part II: application to material behaviors. REEF 1998;7(5):567 88.

[28] Yonezu A, Kuwahara Y, Yoneda K, Hirakata H, Minoshima K. Estimation of the anisotropic plastic property using single spherical indentation an FEM study. Comput Mater Sci 2009;47(2):611 9.

[29] Cheikh M. Reanalysis of structures with modification of the stiffness, application to the modeling of damage in unidirectional composites. Comput Struct 2000;78(5):725 36. 